\title{
Mimicking natural cell environments: design, fabrication and application of bio-chemical gradients on polymeric biomaterial substrates
}

Citation for published version (APA):

Benetti, E. M., Gunnewiek, M. K., van Blitterswijk, C. A., Vancso, G. J., \& Moroni, L. (2016). Mimicking natural cell environments: design, fabrication and application of bio-chemical gradients on polymeric biomaterial substrates. Journal of Materials Chemistry. B, Materials for Biology and Medicine, 4(24), 42444257. https://doi.org/10.1039/c6tb00947f

Document status and date:

Published: 01/01/2016

DOI:

10.1039/c6tb00947f

Document Version:

Publisher's PDF, also known as Version of record

Document license:

Taverne

Please check the document version of this publication:

- A submitted manuscript is the version of the article upon submission and before peer-review. There can be important differences between the submitted version and the official published version of record.

People interested in the research are advised to contact the author for the final version of the publication, or visit the DOI to the publisher's website.

- The final author version and the galley proof are versions of the publication after peer review.

- The final published version features the final layout of the paper including the volume, issue and page numbers.

Link to publication

\footnotetext{
General rights rights.

- You may freely distribute the URL identifying the publication in the public portal. please follow below link for the End User Agreement:

www.umlib.nl/taverne-license

Take down policy

If you believe that this document breaches copyright please contact us at:

repository@maastrichtuniversity.nl

providing details and we will investigate your claim.
}

Copyright and moral rights for the publications made accessible in the public portal are retained by the authors and/or other copyright owners and it is a condition of accessing publications that users recognise and abide by the legal requirements associated with these

- Users may download and print one copy of any publication from the public portal for the purpose of private study or research.

- You may not further distribute the material or use it for any profit-making activity or commercial gain

If the publication is distributed under the terms of Article $25 \mathrm{fa}$ of the Dutch Copyright Act, indicated by the "Taverne" license above, 


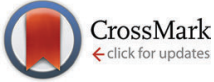

Cite this: J. Mater. Chem. B, 2016, 4, 4244

\section{Mimicking natural cell environments: design, fabrication and application of bio-chemical gradients on polymeric biomaterial substrates}

\author{
Edmondo M. Benetti, ${ }^{\text {ab }}$ Michel Klein Gunnewiek, ${ }^{a}$ Clemens A. van Blitterswijk, \\ G. Julius Vancso ${ }^{a}$ and Lorenzo Moroni*c
}

\begin{abstract}
Gradients of biomolecules on synthetic, solid substrates can efficiently mimic the natural, graded variation of properties of the extracellular matrix (ECM). Such gradients represent accessible study platforms for the understanding of cellular activities, and they also provide functional supports for tissue engineering (TE). This review describes the most relevant methods to produce 2-dimensional (2D) as well as 3-dimensional (3D) gradient supports for cell manipulations, and also addresses the response of cells from different origins when seeded on these constructs. The fabrication strategies summarized encompass the combination of polymer and surface chemistries, micro- and nano-engineering construction strategies and biotechnological approaches. This multidisciplinary scheme has enabled the design and realization of diverse, synthetic supports as cellular environments, spanning from the first gradient self-assembled monolayer (SAM) to multilayers, and hybrid constructs mimicking the complexity of natural tissue environments. The standing challenge is bringing these advances in the fabrication of supports to a dynamic functioning in space and time, towards the successful imitation of the most complex bio-chemical system ever studied: our body.
\end{abstract}

Received 15th April 2016, Accepted 20th May 2016

DOI: 10.1039/c6tb00947f

www.rsc.org/MaterialsB

\section{Introduction}

Current research activities in the development of polymeric biomaterials are progressing towards the design of twodimensional (2D) and three-dimensional (3D) supports presenting a gradual variation of biochemical composition and/or physicochemical properties. This trend is principally driven by the need to closely mimic the natural variation of extra-cellular matrix (ECM) characteristics, including the spatial definition of the behavior of seeded cells on the synthetic supports. ${ }^{1,2}$ Scaffolds of various compositions and presenting gradient properties have the capability of triggering several biological processes like cell migration via haptotaxis ${ }^{3}$ and durotaxis. ${ }^{4}$ Alternatively, gradient-containing supports can be applied to closely reproduce the physical properties of their natural tissue counterparts, simultaneously hosting tissue-(re)forming cells, like in the case

\footnotetext{
${ }^{a}$ Department of Materials Science and Technology of Polymers, MESA+ Institute for Nanotechnology, University of Twente, P.O. Box 217, 7500 AE Enschede, The Netherlands

${ }^{b}$ Laboratory for Surface Science and Technology (LSST), Department of Materials, ETH Zürich, CH-8093 Zürich, Vladimir-Prelog-Weg 5, Switzerland.

E-mail:edmondo.benetti@mat.ethz.ch

${ }^{c}$ Department of Complex Tissue Regeneration, MERLN Institute for Technology

Inspired Regenerative Medicine, Maastricht University, P.O. Box 616,

6200 MD Maastricht, The Netherlands
}

of gradient hydrogel supports replacing the damaged parts of bone-cartilage joints. ${ }^{1,5}$

In both these cases, the engineering and fabrication of synthetic ECMs encompass the spatial variation of at least one support's characteristic, either chemical (e.g. protein concentration ${ }^{6,7}$ or hydrophilicity $\left.{ }^{8}\right)$, physical (e.g. matrix stiffness $\left.{ }^{9}\right)$ or morphological $\left(\right.$ porosity $\left.{ }^{10}\right)$.

The design of 2D platforms presenting bio-chemical gradients largely relied on the controlled surface deposition of proteins by physisorption or covalent attachment, and often included the application of (macro)molecular "spacers", such as self-assembled monolayers (SAMs) or polymer brushes, on inorganic surfaces. ${ }^{2,11}$ In contrast, 3D supports featuring gradient compositions ${ }^{12-14}$ have been mainly fabricated starting from hydrogel materials, using poly(ethylene glycol) (PEG) derivatives, for instance, and decorating the synthetic matrix with biomolecules or specific cellular cues via controlled loading. ${ }^{14-17}$ Additionally, 3D porous scaffolds for tissue engineering (TE) formulations have been developed by a number of diverse fabrication methods, to yield controlled and gradual variations of macro, micro and nanoporosities. The so-created morphological gradients regulated the settlement of cells, the diffusion of nutrients and the removal of cellular waste products during cell proliferation and differentiation, also providing a progressive variation of mechanical properties within the whole support. ${ }^{18-22}$ 
In this review, we firstly focus on the most relevant strategies to synthesize $2 \mathrm{D}$ gradients, concentrating on the applications of polymer adlayers and brushes to trigger the controlled surface functionalization of various biomolecules. Secondly, we report the latest advances in engineering and fabricating 3D hydrogel and porous supports presenting gradients of composition and/or physical properties. The application of both $2 \mathrm{D}$ and $3 \mathrm{D}$ constructs for studying the response of cells from different origins and for the support-mediated regeneration of tissues is finally reported.

\section{D protein gradients supported by SAMs and polymer brushes}

The first example of an unidirectional chemical gradient on a silicon oxide surface was presented in 1992 by Chaudhury and Whitesides, who exploited vapour deposition of different silane-based adsorbates to create SAMs featuring gradient-like surface concentrations of hydrophobic species. ${ }^{23}$ Inspired by these pioneering fabrication methods, several mixed SAM compositions were subsequently employed as platforms for the

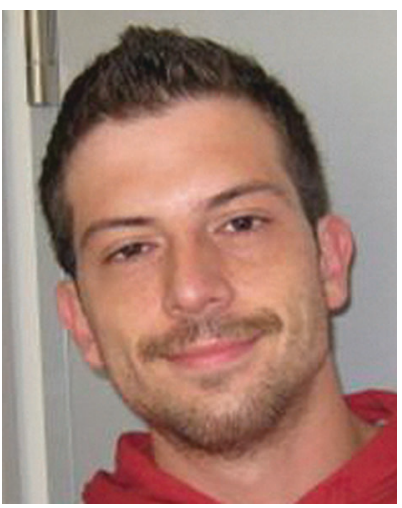

Edmondo M. Benetti
Edmondo M. Benetti graduated in chemistry at the University of Padova (Italy) in 2004 and he carried out his PhD at the University of Twente (The Netherlands), working in the Department of Materials Science and Technology of Polymers (2009). He joined the Department of Materials at ETH in 2009 as a PostDoc working in the groups of Prof. Nicholas Spencer and Prof. Marcus Textor. Since 2014 he has been a Senior Scientist in the

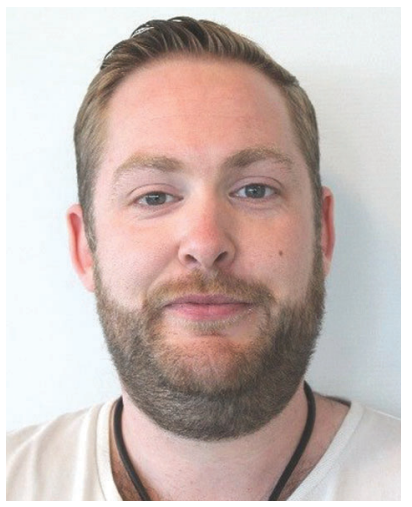

Michel Klein Gunnewiek
Michel Klein Gunnewiek is a PhD student in the Department of Materials Science and Technology of Polymers at the University of Twente, working under the supervision of Prof. Dr G. J. Vancso and Dr E. M. Benetti. He received a master's degree in Chemical Engineering from the University of Twente in 2010. His research focuses on the fabrication of polymer brush coatings on biodegradable polyester-based supports featuring both $2 D$ and $3 D$ scaffolds.

Laboratory For Surface Science and Technology. Here he focuses his research activities on controlled polymerization methods to synthesize polymeric surface modifiers with controlled architecture and composition. These materials are particularly applied for the functionalization of multidimensional surfaces to regulate their interaction with biological media.

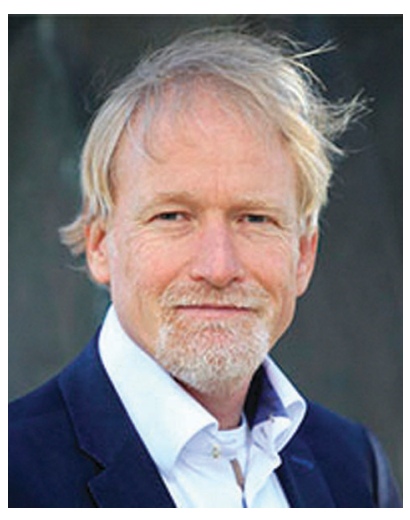

Clemens A. van Blitterswijk
Clemens van Blitterswijk graduated as a cell biologist at Leiden University in 1982 and defended his PhD thesis in 1985 at the same university. At present, most of his research focuses on tissue engineering and regenerative medicine, forming a unique basis of multidisciplinary research between materials and life sciences. He holds the Chairholder position at MERLN Institute for Technology-Inspired Regenerative Medicine at Maastricht University in the Netherlands. During his career, Prof. van Blitterswijk has cofounded several biomedical companies and held several functions in these organizations. Today, he combines his Professorship at Maastricht with a Founding Partnership of the new LSP-Health Economics Fund (LSP-HEF) of the European health care investment group Life Sciences Partners (LSP).

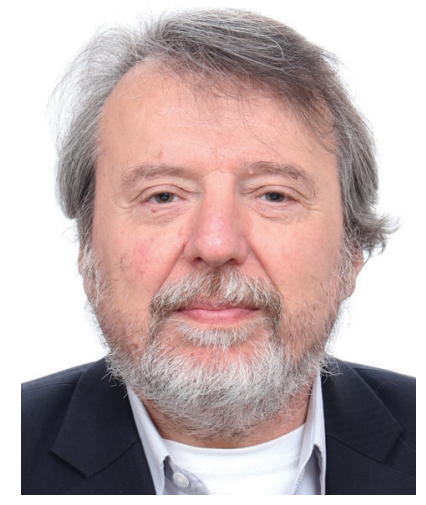

G. Julius Vancso
G. Julius Vancso studied physics and materials science at the University of Budapest, Hungary, and at the Swiss Federal Institute of Technology (ETH-Zürich), and holds a PhD in solid state physics. Following a tenured faculty appointment at the University of Toronto he joined the University of Twente in the Netherlands in 1994 and is at present Professor and Chairholder in Polymer Materials Science and Technology. He carries out his research in the MESA+ Institute for Nanotechnology of the same university. His current interests involve materials science of smart soft matter for applications in biomaterials and medicine, fluidics and sensing; single molecule studies, surface engineering with polymers, and materials chemistry of organometallic polymers. 
formation of surface gradients of adsorbed proteins on gold substrates. For instance, Tirrell et al. reported the preparation of a surface concentration gradient of hydrophobic, proteinadhesive thiol species. By this method, a first SAM was uniformly deposited on $\mathrm{Au}$, followed by the electrochemistry-assisted desorption of the constituting thiol species, which could be spatially controlled through the application of a decaying potential window across the functionalized substrate. ${ }^{24}$ The so-obtained surface gradient of thiol coverage was subsequently "back-filled" with biopassive, oligoethylene glycol-bearing thiols, finally yielding a gradual variation of the bio-adhesive character across the surface. ${ }^{24-27}$ On this SAM, protein adsorption could be spatially controlled along the gradient, enabling the fabrication of a unidirectional variation of protein surface density. ${ }^{28,29}$

More recently, Bonifazi et al. ${ }^{30}$ fabricated gradients of SAMs by varying the exposure time of single Au substrates in solution mixtures of peptide-exposing thiol ligands, featuring the cellmigration stimulating factor Ile-Gly-Asp-Gln (IGDQ), and bioinert thiol species. ${ }^{31}$ The so-formed gradient mixed monolayers were subsequently applied to investigate the migratory behavior of metastatic breast cancer cells compared to human dermal fibroblasts. An individual rather than a collective cancer cell migration was thus highlighted, suggesting the coexistence of "stationary" and "migrating" cell phenotypes.

SAMs presenting a gradual variation of chemical composition on silicon oxide and gold substrates were also applied for the subsequent surface-initiated polymerization (SIP) to form polymerbrush, grafting-density gradients (Fig. 1). ${ }^{32-36}$ The fabrication of these polymeric supports typically relied on the preliminary formation of a SAM of initiator adsorbates presenting a gradient coverage across a single substrate (Fig. 1a). Subsequent SIP

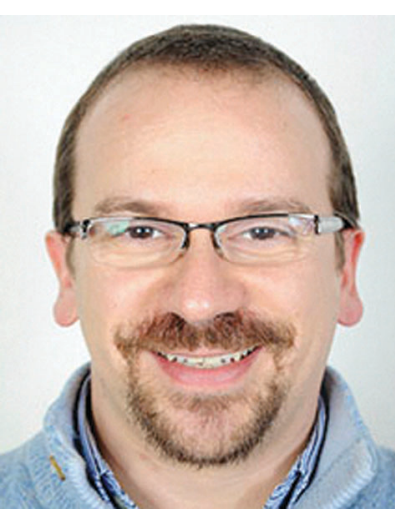

Lorenzo Moroni
Lorenzo Moroni studied Biomedical Engineering at the Polytechnic University of Milan, Italy, and Nanoscale Sciences at Chalmers Technical University, Sweden. He received his $\mathrm{PhD}$ cum laude in 2006 at the University of Twente. In 2007, he worked at Johns Hopkins University as a postdoctoral fellow in the Elisseeff lab, focusing on hydrogels and stem cells. In 2008, he was appointed the $R \& D$ director of the Musculoskeletal Tissue Bank of

Rizzoli Orthopedic Institute. From 2009 to 2014, he joined again the University of Twente, where he got tenured in the Tissue Regeneration department. Since 2014 he has worked at Maastricht University and in 2016 he became a professor of biofabrication for regenerative medicine at the MERLN Institute for Technology-Inspired Regenerative Medicine. His research group aims at developing biofabrication technologies to generate libraries of $3 D$ scaffolds able to control cell fate. a-i)

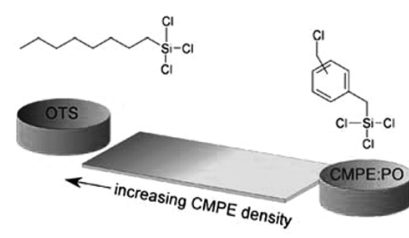

a-ii)
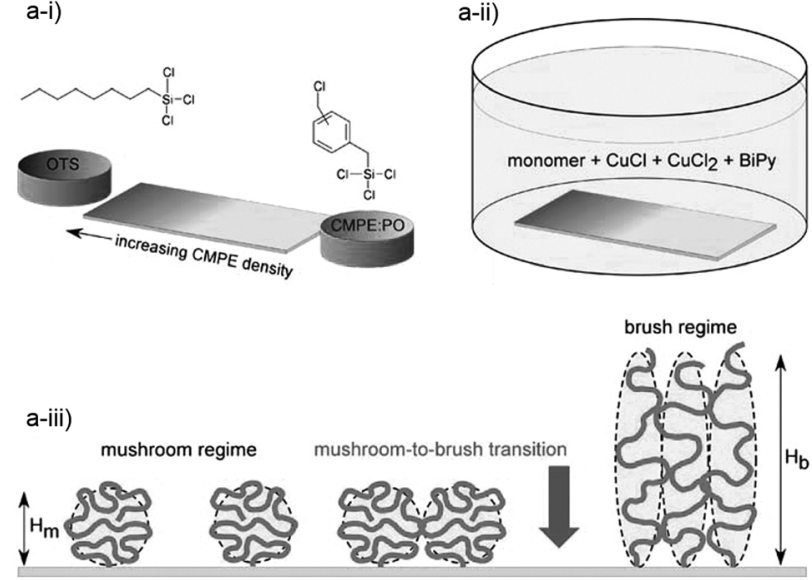

b)

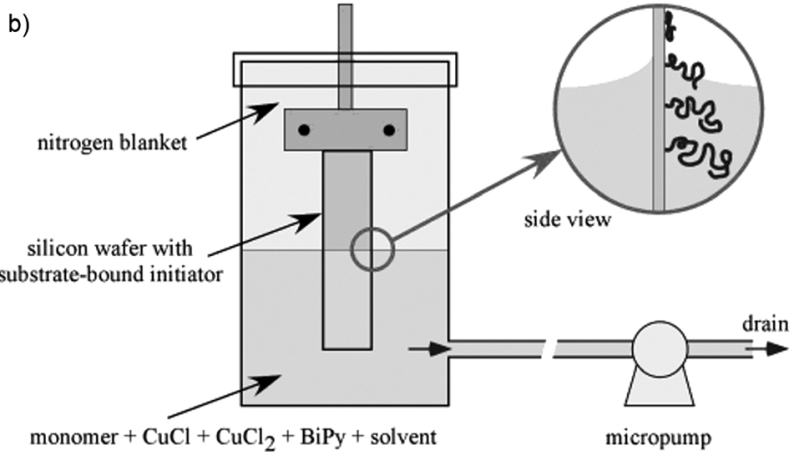

Fig. 1 (a) Preparation of a SIP initiator gradient by controlled deposition on silicon oxide surfaces. (b) Surface-grafted polymer brushes presenting a gradient in grafting densities are subsequently formed by SI-ATRP. (c) Schematic illustrating grafted polymer conformations in the mushroom and brush regimes, and the mushroom-to-brush transition. Adapted with permission of Springer, ref. 49. (d) Schematic of the setup for the fabrication of surface grafted polymer brushes with a gradient in molecular weight. Adapted with permission from ref. 50. Copyright 2003 American Chemical Society

(Fig. 1b) produced a graded variation of polymer grafting density along the sample, obtaining layers of grafts progressively shifting their conformation from low-density mushrooms towards highdensity brushes (Fig. 1c). ${ }^{37-39}$

Similar polymer brush platforms were successfully employed to study protein and cell adhesion, and to dissect the influence of brush-design parameters on bio-adhesion. ${ }^{40-45} \mathrm{~A}$ relevant example was provided by poly(2-hydroxyethyl methacrylate) (PHEMA) grafts presenting a gradual variation of grafting densities and chain lengths, which were later on applied as biointerfaces by the group of Genzer. ${ }^{46,47}$ Orthogonal double gradients of both PHEMA grafting density and brush molar mass were fabricated by applying mixed initiator SAMs showing a gradual variation of initiator coverages along one substrate direction, coupled with a progressive increase in the applied polymerization time (by varying substrate-polymerization solution contact time) (Fig. 1d) along the direction orthogonal to the first gradient. The so-created brush platforms were subsequently incubated in fibronectin (FN) solutions, demonstrating how thick and dense PHEMA brushes significantly inhibited the adsorption of this protein, while, for a given grafted chain-length, a progressive increase of adsorbed FN could be obtained by gradually decreasing the grafting 
density of PHEMA films. Hence, the PHEMA brush orthogonal gradients translated into surface gradients of physisorbed FN and were finally tested for monitoring the adhesion of MCT3T-E1 cells, which promptly responded to the bi-directional variation of surface coverage by adhesive cues, displaying a progressive change of cell number and spreading area along the substrate.

The functionalization of biomaterial surfaces by graftedfrom, gradient polymer brushes has been not only devoted to study and prevent the adsorption of proteins, but also to create cell-adhesive interfaces, which can trigger in a spatially-defined way specific cellular responses. Thickness gradients of thermoresponsive poly- $N$-(isopropylacrylamide) (PNIPAM) brushes, fabricated following the Genzer's method, were applied for studying the adhesion of human liver cancer cells (HepG2) above the lower critical solution temperature (LCST) of PNIPAM, and their subsequent detachment below LCST. ${ }^{48}$ The so-fabricated gradient brushes allowed a spatial modulation of the reversibility of cell adhesion. Namely, for a specific range of PNIPAM brush thicknesses across the gradient, HepG2 cells were shown to promptly adhere at temperatures above $37{ }^{\circ} \mathrm{C}$, and nearly quantitatively detach at $24^{\circ} \mathrm{C}$.

The application of polymer brush gradients for tuning cell attachment was recently investigated by the groups of Benetti, Vancso and Moroni, which fabricated poly(oligoethylene glycol)methacrylate (POEGMA) brush platforms presenting a gradual variation of tethered-chain length (brush thickness) and bearing cell-adhesive FN units to regulate the mechanisms of settlement by human mesenchymal stem cells (hMSCs). ${ }^{51}$

In this study, the variation of POEGMA brush thickness within the 10-60 $\mathrm{nm}$ range along a single substrate was achieved by surface-initiated atom transfer radical polymerization (SI-ATRP) from initiator-functionalized poly- $\varepsilon$-caprolactone (PCL) surfaces, and by gradually varying the exposure time of the initiating substrates to the polymerization medium. Subsequent functionalization of the POEGMA brushes by FN produced cell-adhesive platforms presenting constant protein coverage, grafting density and solvent content but also displaying a progressive variation of the brush-tether length. This translated into a gradient of frictional dissipation and brush lateral deformability along the surface, where thicker brushes could be more laterally deformed and showed higher friction, as measured by lateral force microscopy (LFM), while thinner ones showed reduced shear deformability and lower frictional dissipation. The gradual variation of these properties was demonstrated to alter the adhesion and spreading of hMSCs, which responded to the modulation of the dissipative character by POEGMA-FN adducts. Following a direct relationship, hMSC area progressively decreased with the increasing of POEGMA brush lateral deformability (expressed as maximum brush lateral strain), indicating that the dissipative character of brush-cue adducts and cell spreading are synergistically correlated. $^{52-55}$ The different strengths of cell adhesion along the brush gradient were also reflected by a variation of the morphology and distribution of focal adhesion complexes (FAs) across the cell membranes.

As displayed in Fig. 2, on thinner brushes larger and oriented FAs were delocalized over the whole cell membrane.
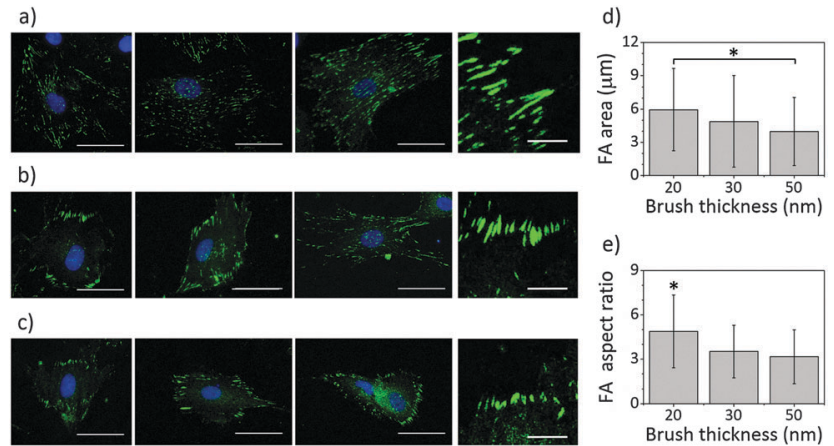

Fig. 2 Immunofluorescence micrographs showing the vinculin-associated FA complexes for hMSCs attached on 10-20 (a), 30-40 (b) and 50-60 (c) $\mathrm{nm}$-thick POEGMA brushes functionalized with FN. The FA points were stained by FITC (green) and the cell nucleus by DAPI (blue). (d) Average FA area and (e) average FA aspect ratio. * denotes statistical significant differences between the assigned and the non-assigned topographies $(p<0.05)$. Adapted with permission from ref. 51. Copyright 2015 WileyVCH Verlag GmbH \& Co.

With increasing brush thickness, smaller FAs were increasingly concentrated at the periphery of the membrane. Hence, a gradual variation of brush parameters was demonstrated to regulate the adhesion and spreading of stem cells. These findings additionally suggested that brush gradients could be effectively applied in more complex preparations with the aim of directing cell proliferation and, ultimately, differentiation. Following an alternative preparation of brush films, based on a grafting-to method, the group of Spencer applied poly(L-lysine)graft-PEG graft-copolymers (PLL-g-PEG) to form thin PEG-brush layers on titanium oxide $\left(\mathrm{TiO}_{2}\right)$ surfaces. ${ }^{56}$ Due to the electrostatic interactions between the positively charged PLL backbones and the negatively charged $\mathrm{TiO}_{2}$ surface, and by varying the exposure time of the adsorbing polymer solutions along the substrate, a gradient in the surface density of the adsorbed copolymer was easily obtained. This translated into a gradual variation of PEG surface density, which was expressed as concentration of EG-units across the formed gradient, ranging from 0 to around 17 EG-units $\mathrm{nm}^{-2}$. These platforms were subsequently applied to spatially control the adsorption of bovine serum albumin (BSA) and fibrinogen (Fgn). ${ }^{57}$ Although the adsorption of both these proteins gradually decreased with increasing EG density, quantitative inhibition of Fgn adsorption required higher PEG coverage (EG-units $=12.8 \pm 0.6 \mathrm{~nm}^{-2}$ ) compared to BSA (EG-units $=8.3 \pm 0.8 \mathrm{~nm}^{-2}$ ). These differences in adsorption behavior between BSA and Fgn were attributed to the lower energy cost for Fgn to adhere between PEG chains (or on film defects), provided by the distinctive morphology of this coil-like protein, capable of undergoing secondary adsorption on too thin or non-uniform brush films. ${ }^{58}$ The remarkable advantage of this brush gradient fabrication strategy, compared to the already reported grafting-from methods, is represented by its easy and reproducible dip-and-rinse process and the possibility to coat large surfaces in a controlled fashion. Additionally, structured PLL- $g$-PEG films can be applied not only on metal oxide surfaces but also on glass and silicon oxide substrates. ${ }^{59,60}$ 


\section{Microfluidic-assisted fabrication of 2D gradients on hydrogel substrates}

As hydrogel supports have been often applied as highly versatile platforms for regulating the settlement of cells and studying their behavior in response to chemical or physical stimuli, ${ }^{61,62}$ the surface engineering of these substrates has progressively gained increasing impact in the development of biomaterials. Novel surface modification/functionalization strategies exploiting microfluidic devices to deposit (bio)chemical species in a spatially controlled fashion have recently emerged as powerful alternatives compared to the commonly applied "static" solution treatments.

Particularly, the formation of lamellar flows of protein solutions inside microchannels ${ }^{63,64}$ was successfully applied to physically or chemically deposit proteins and other biomolecules onto hydrogel surfaces placed in contact with the flow (Fig. 3a and b). ${ }^{63-67}$ Gradients of adsorbed proteins on poly(dimethylsiloxane) (PDMS) substrates were similarly fabricated by exploiting the progressive depletion of protein concentration in the fluid channel, ${ }^{63,68}$ which finally yielded surface concentration gradients of biomolecules with typical extensions ranging from sub-micrometer to several centimetres in length (Fig. 3c). ${ }^{69}$ Following a similar approach, yet employing multichannel devices, patterns of different proteins could be formed, finally obtaining multiple gradient arrays and double gradients featuring two different protein species on glass supports, as shown in Fig. 3d. ${ }^{68}$

Protein gradients on hydrogels can be fabricated also along the width of microchannels by injecting two or more protein solutions into a fluidic-based system composed of alternated splitting and mixing units. ${ }^{64,70,71}$ When two inlets were used, one containing a protein solution and the second just a buffer solution, a single gradient of one protein was formed between the walls. Alternatively, the addition of a solution of a second protein through an additional inlet allowed the fabrication of hydrogels featuring concentration gradients of two different proteins. ${ }^{72}$ The designing of microfluidic devices presenting three or more inlets additionally enabled the fabrication of more complex, multiple-protein concentration profiles. ${ }^{64}$

Another gradient fabrication technique based on microfluidics was introduced by the group of Lutolf, which exploited hydrodynamic flow focusing (HFF) to create protein gradients on PEGhydrogel surfaces through protein-specific binding functions (Fig. 4a). ${ }^{73}$ In this method, NeutrAvidin-decorated PEG-hydrogels were functionalized by different biotinylated biomolecules flowing through a microchannel system presenting three independently controlled inlets.

The composition and the morphology of the subsequently formed surface gradients could be efficiently controlled by adjusting the flow rates in the individual channels, which also determined the width and the position of the different protein solution streams (Fig. 4b-d)..$^{7,74}$

The above-mentioned fabrication methods relied on the variations of surface exposure times by one or more protein solution streams. Alternatively, a gradual modulation of protein concentration within a flow, coupled with the application of diverse protein media via multiple injection steps, was employed a

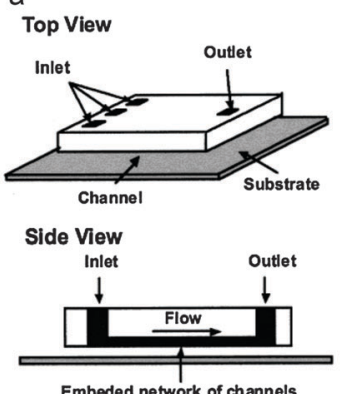

Embeded network of channels b

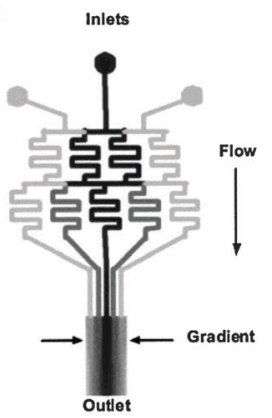

C
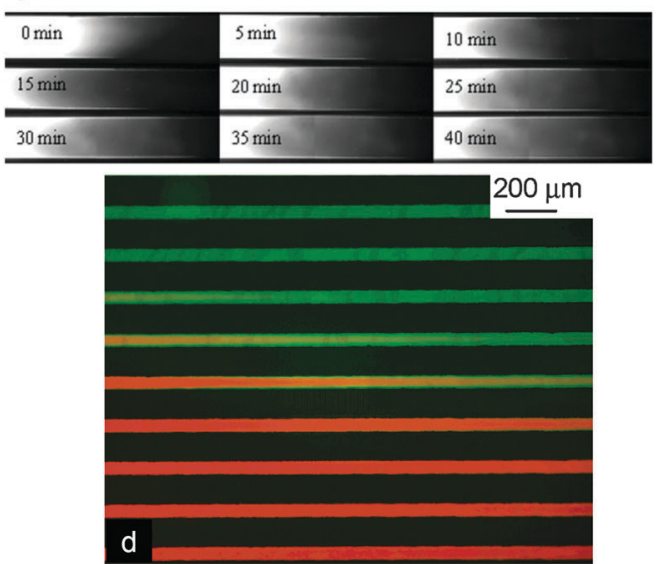

Fig. 3 (a) A microfluidic gradient generator setup and (b) a schematic design of a gradient-generating microfluidic network using three inlets. Adapted with permission from ref. 64. Copyright 2000 American Chemical Society. (c) Fluorescence micrographs depicting an example of the fabricated gradients at different backward-flow times. Adapted with permission from ref. 69. Copyright 2010 Wiley-VCH Verlag GmbH \& Co. (d) Counterpropagating gradient of BSA (orange-red) and collagen (green) with pre-exposure of PDMS to BSA. Adapted with permission from ref. 68 . Copyright 2003 American Chemical Society.

to design complex protein patterns and gradients on similar hydrogel surfaces. ${ }^{73-75}$

This fabrication strategy was experimented by the same research group of Lutolf, which created patterns of four parallel, linear gradients of fluorescently-labelled human immunoglobulin (hIgG) with micrometer precision on PEG gel substrates (Fig. 5a and b). Following a first solution flow-assisted deposition, the simple rotation of the pre-functionalized chip by $90^{\circ}$ (Fig. 5c) allowed the formation of four additional micropatterns of BSAbiotin concentration gradients, finally obtaining an array of orthogonally intersecting gradient patterns (Fig. 5d and e).

The application of microfluidic techniques to create surfacegradients of biomolecules demonstrated a highly powerful and versatile engineering approach to structure with high precision and reproducibility a variety of hydrogel and elastomeric substrates. These attracting advantages unfortunately suffered from some limitations, mainly related to the impossibility to structure areas on substrates larger than a few centimetres.

This drawback restricted the applicability of such methods to design study-platforms for addressing isolated biological phenomena without having the capability of scaling-up these 
a

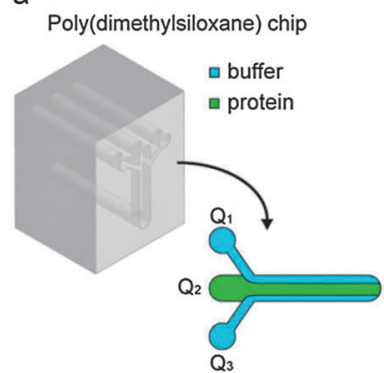

b
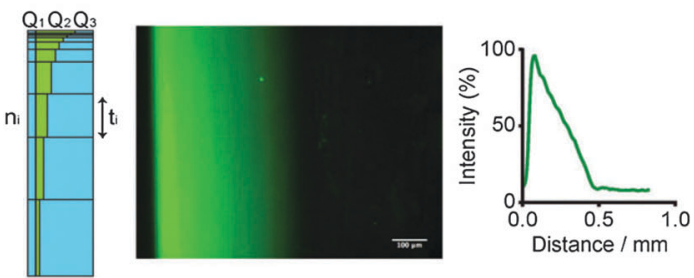

C
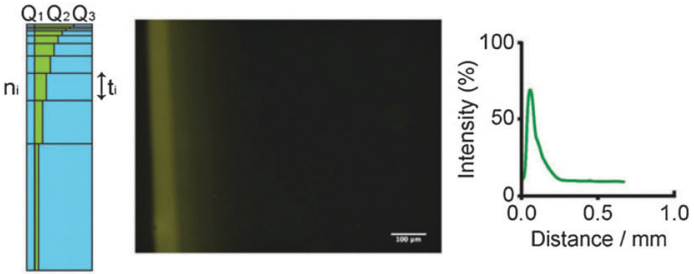

d
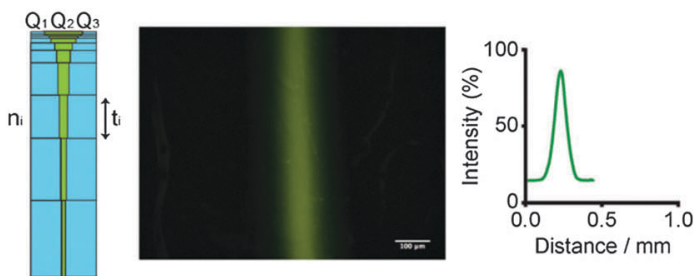

Fig. 4 (a) A microfluidic chip used for hydrodynamic flow focusing Fluorescence micrographs and graphical representations obtained by image analysis of a (b) linear, (c) exponential and (d) Gaussian gradients of FITC-BSA-Biotin on NeutrAdvidin-conjugated PEG gels (scale bar = $100 \mathrm{~mm}$ ). Adapted from ref. 73 with permission of The Royal Society of Chemistry.

fabrication methods for the structuring of macroscopic supports for TE. In the following paragraph, alternative fabrication methods for producing gradient supports from $2 \mathrm{D}$ to $3 \mathrm{D}$ that can be extended to build large scaffolds maintaining very high feature resolutions are presented.

\section{D gradients on porous scaffolds}

The increasing applications of porous scaffolds in TE formulations stimulated the development of fabrication/surface modification methods allowing the formation of $3 \mathrm{D}$ (bio)chemical gradients within these supports.

The large majority of the most advanced methods to create $3 \mathrm{D}$ gradients on porous scaffolds directly derived from analogous surface functionalization strategies applied for flat surfaces,
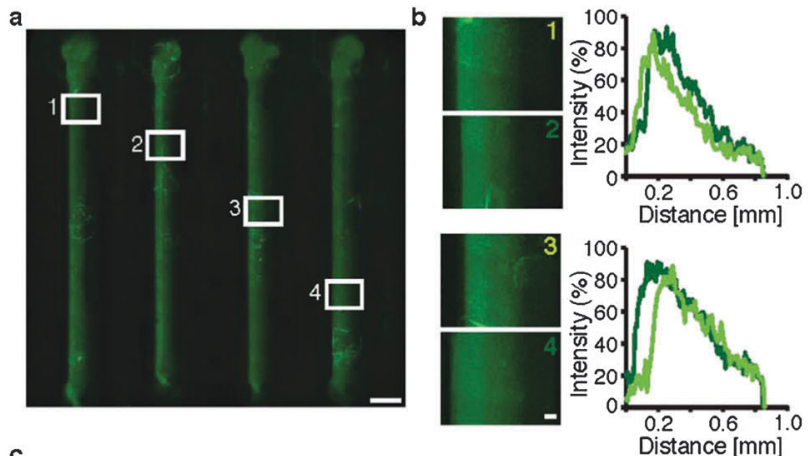

c
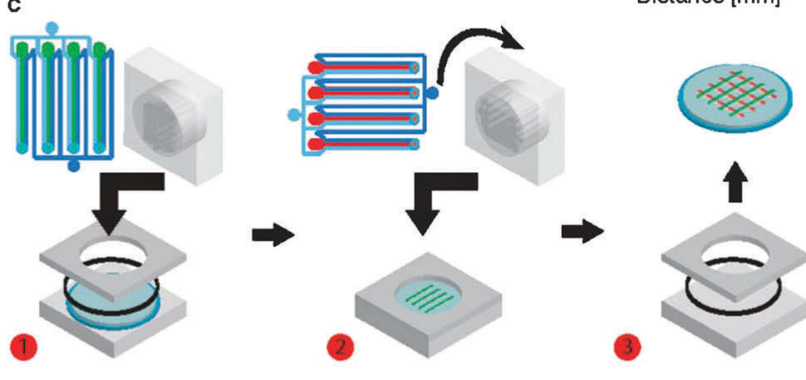

d
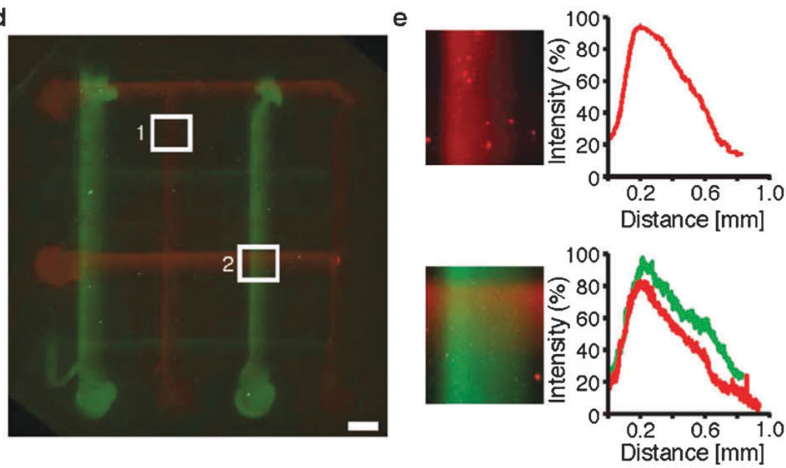

Fig. 5 (a) Stitched micrographs of a pattern of four parallel arrayed protein gradients. (b) Micrographs showing the magnification of individual gradients (white frames) and a graphical representation of their respective intensity profiles (scale bar $=100 \mathrm{~mm}$ ). (c) Patterning of arrays presenting overlapping gradients. Step 1: the microfluidic device is assembled and the first set of four gradients is patterned. Step 2: the microfluidic device is partially disassembled with the patterned hydrogel remaining fixed to ensure good alignment. The microfluidic chip is turned by $90^{\circ}$ and the second set of parallel gradients is deposited. Step 3: the patterned hydrogel is recovered. (d) Stitched micrographs of a four-by-four gradient array of two different proteins. (Scale bar $=900 \mathrm{~mm}$ ). (e) Micrographs of the regions of interest of the gradient array (white frames) and a graphical representation of the corresponding intensity profiles. Reproduced from ref. 74 with permission of The Royal Society of Chemistry.

additionally expanding substrate structuring in the third dimension or coupling controlled, layer-by-layer depositions of single constituents to finally yield three-dimensional constructs. This is the case of electrospinning, ${ }^{22}$ a well-known process to fabricate porous constructs. In this method, the application of a high voltage is exploited to create an electrically charged flow of a polymer solution or a polymer melt from a nozzle to a collector plate. ${ }^{76}$ As the polymer solidifies, it forms an interconnected porous web of fibers. Electrospun constructs featuring gradient chemistries and/or physical properties have been manufactured by gradually varying the composition of the electrospinning 
solution at a single nozzle. This strategy was explored by applying several different setups, which basically exploited the same principle of progressive mixing of electrospinning feeds. These included the "gradient maker", 77 a microfluidic device dispensing polymer solutions with varying compositions ${ }^{78}$ or, alternatively, a setup where two polymer solutions mix in different proportions at a T-junction. ${ }^{79}$

Compositional gradients of electrospun fiber mats could be also obtained by a double electrospinning process, as exemplarily shown in Fig. $6 .^{80}$ In this case two spinnerets were placed at the opposite side of a rotating drum and the flow rate of both solutions was varied independently. ${ }^{81,82}$ Keeping steady the collector plate or the rotating drum at a certain position, a compositional gradient along the vertical axis of the construct was successfully fabricated. Additional lateral movement of the spinneret along the drum allowed the formation of an additional gradient of fiber composition along the horizontal axis of the scaffold. ${ }^{83,84}$

Using similar apparatuses, gradient electrospun scaffolds including different proteins incorporated within the fiber structures could be also created. The embodied biomolecules were subsequently released in the surrounding medium, ${ }^{77,78,83,85}$ or, alternatively, remained anchored to the fiber surface (via heparin-mediated linkages, as an example). ${ }^{84}$

Following alternative, fiber-surface functionalization strategies, the gradual diffusion of calcium phosphate, ${ }^{86}$ proteins, ${ }^{87}$ or aminolysis $^{88}$ solutions within the pre-formed electrospun polymer supports was reported to allow the chemical modification of the support according to a gradient morphology. In all these cases, due to the high porosity of the fiber mats, solutions of adsorbates or reactants could diffuse by capillarity into the support and create a unidirectional, compositional gradient throughout the 3D structure. As an example, the group of Chen applied the controlled diffusion of protein solutions within a poly(methylglutarimide) (PMGI) fiber network, successfully producing 3D gradients of physisorbed FN. ${ }^{87}$ By additionally varying the diffusion speed as well as the FN concentration in the diffusing solutions, the efficient modulation of FN gradient coverages throughout the constructs could be achieved. In a similar way, the group of $\mathrm{Li}$ created a gradient of amino functions at the fibers' surface by varying the aminolysis time across the structure of a poly(DLlactide) (PDLLA) electrospun fiber mat. ${ }^{88}$ The exposed amino groups were subsequently coupled to gelatin units, finally forming a gradient of biomolecules within the 3D support.

Controlled diffusion of surface modifiers and/or biomolecules could be also applied to form compositional 3D gradients within

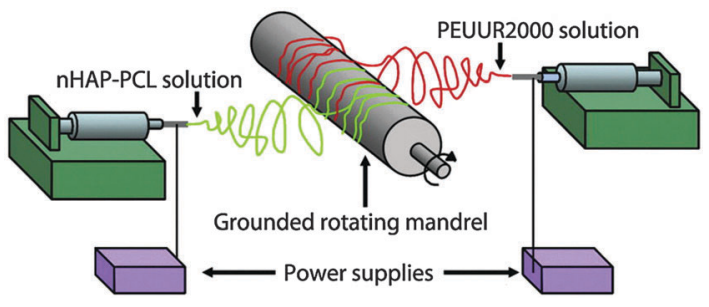

Fig. 6 Schematic illustrating an electrospinning apparatus with offset spinnerets. Reprinted from ref. 80, Copyright 2011, with permission from Elsevier. microporous constructs initially obtained by other fabrication methods.

Multidirectional gradients of two different growth factors (GFs) within microporous PCL membranes, previously obtained by an immersion/precipitation method, ${ }^{90}$ could be formed by controlled diffusion and heparin-mediated adsorption of proteins, as demonstrated by the group of Lee (Fig. 7). ${ }^{89}$ Applying a comparable diffusion-aided functionalization strategy, scaffolds fabricated by the centrifugation of PCL fibrils to form 3D structures featuring a mono-directional gradient of porosity could be decorated with GFs via heparin-binding. ${ }^{89,91-94}$ An increment of surface concentration of GFs on the fiber constituents thus reflected an increase of the available surface area along the porosity gradient. This effective fabrication paved the way for possible further developments in the gradient composition (e.g. the application of multiple GFs within the same construct) or in the formation of double gradients, including both porosity and protein composition/concentration.

The fabrication of multi-directional, 3D gradients of different proteins within biodegradable scaffolds has represented a fundamental step forward to the designing of synthetic ECMs more closely mimicking the natural counterparts, and could gain an enormous impact for regenerative medicine. Pursuing this challenging objective, the groups of Benetti, Vancso and Moroni recently reported the fabrication of $3 \mathrm{D}$ gradient scaffolds by a combination of rapid prototyping (RP) of biodegradable thermoplastics ${ }^{95,96}$ and their subsequent functionalization by SI-ATRP of POEGMA (Fig. 8). ${ }^{97}$ Due to the regular microporosity of the supports, provided by RP, and the high surface energy of their exposed surface, assured by the hydrophilic POEGMA brush coatings, the diffusion of different protein solutions could be precisely controlled within the construct in a multidirectional fashion. This allowed creating radial and axial gradients of two different proteins in the same support. The application of similar controlled depositions, utilizing FN solutions within POEGMAcoated PCL scaffolds, allowed the formation of FN-based multidirectional gradients, which could spatially direct the settlement of adhering stem cells with extraordinary precision. The advantage of this fabrication method, as compared to e.g. functional hydrogel supports, was the ease of preparation and the capability of forming multiaxial gradients of proteins keeping full control over gradient characteristics and morphology.

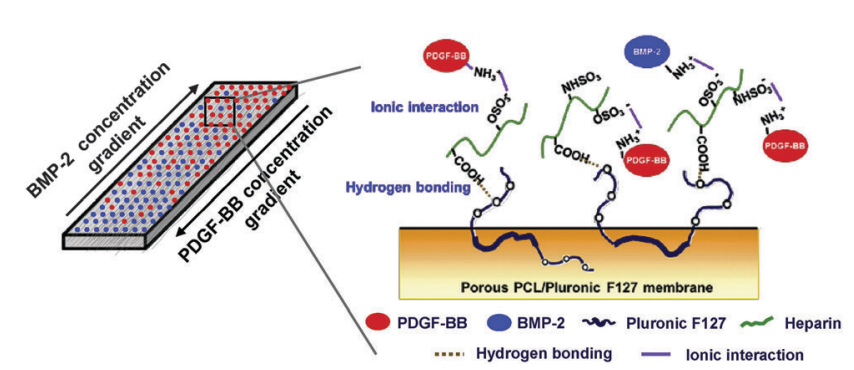

Fig. 7 The formation of a PCL/Pluronic F127 membrane with reverse gradients of PDGF-BB and BMP-2, and the successive binding of heparin and growth factors onto the membrane surface. Reprinted under permission from ref. 89, Copyright 2014, with permission from Elsevier. 


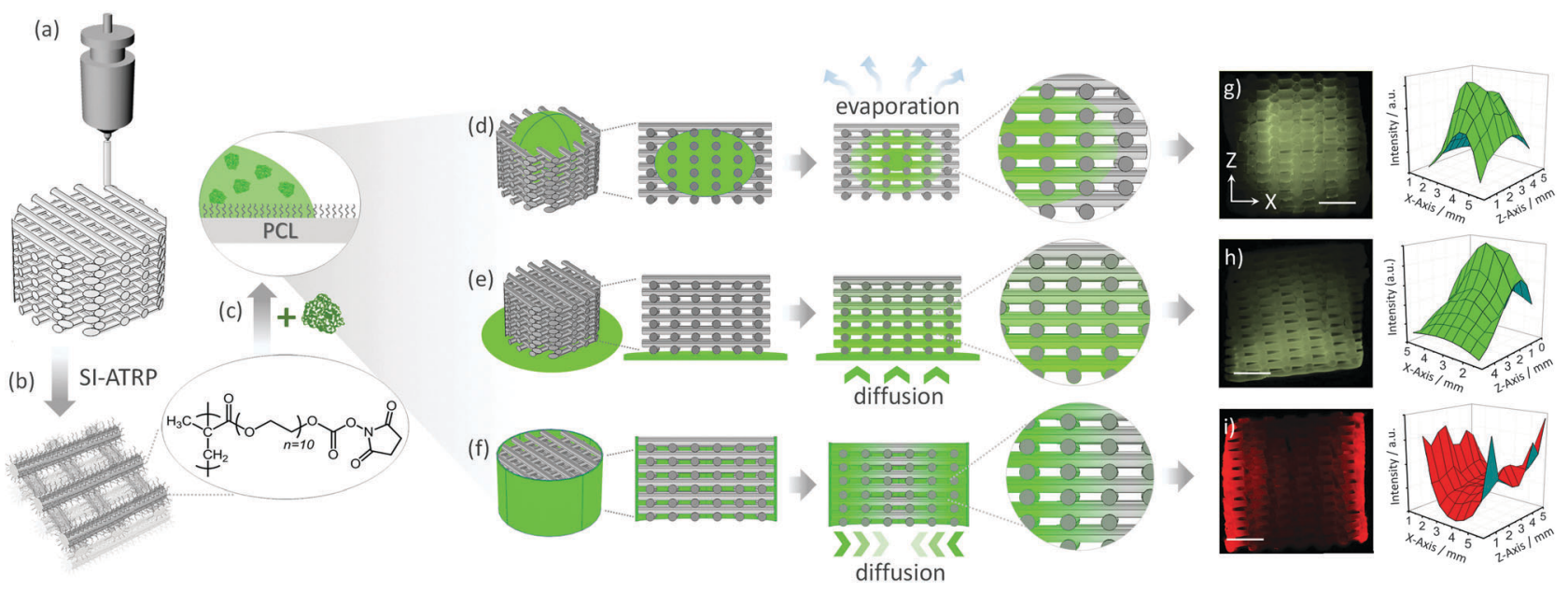

Fig. 8 POEGMA-brush-assisted fabrication of 3D protein gradients within PCL scaffolds. (a) Fabrication of PCL microporous scaffolds by rapid prototyping; (b) SI-ATRP of OEGMA from the PCL fiber network and subsequent activation of hydroxyl side chains to form NHS esters; (c) conjugation of proteins at the brush interface by controlled diffusion of solutions within the 3D scaffolds. This last step is especially highlighted in (d-f). (d) Incorporation of microdroplets of protein solutions and subsequent solvent evaporation generated radial concentration gradients on brushes. (e) Controlled diffusion from a soaked paper reservoir allowed the formation of axial protein concentration gradients. (f) Wrapped soaked paper reservoirs enabled protein diffusion from the lateral walls of the scaffolds and the consequent fabrication of radial protein gradients developing oppositely to (d). Fluorescence micrographs and the corresponding fluorescence intensity plots of PCL-POEGMA scaffolds functionalized with gradients of BSA concentration in the (g) inside-to-outside, (h) bottom-to-top and (i) outside-to-inside directions. Adapted with permission of ref. 97. Copyright 2015 Wiley-VCH Verlag $\mathrm{GmbH} \& \mathrm{Co}$

\section{D gradients within hydrogel supports}

Despite the high potential and attractive properties of microporous thermoplastic supports, hydrogel-based constructs presenting gradient compositions are still intensively developed by numerous research groups worldwide and hold some unique features. Noteworthily, the composition of hydrogels is highly tunable, enabling the introduction of diverse functions for protein immobilization and the tailoring of the construct biodegradability.

In addition, (stem) cell preparations can be directly blended within the hydrogel matrices, during their construction, allowing the manufacturing of injectable pre-tissues in a single fabrication step. Generally, the construction of hydrogels featuring a gradual variation of composition in $3 \mathrm{D}$ has encompassed either (i) the deposition of pre-polymer solutions with progressively varying composition, followed by crosslinking and "fixation" of the whole matrix or (ii) the application of a physico-chemical stimulus within or on a pre-formed hydrogel matrix, capable of spatially propagating a structural or chemical modification of the support along one or multiple directions. In the first class of fabrication strategies lies the "gradient maker" technique, which has been recently developed by the group of West. ${ }^{6}$ In this method, the controlled moulding of hydrogel precursors is accomplished by utilizing an apparatus made of two interconnected chambers that contain different pre-polymer solutions, as exemplified in Fig. 9a. As the solution in chamber 1 is drained from the apparatus into a mould, it is simultaneously re-filled with the solution coming from chamber 2 . While chamber 1 is continuously stirred, it is progressively diluted with the solution from chamber 2 until the outflowing material nearly reaches the composition of this last chamber. Applying photocurable hydrogel precursors and subjecting the moulded constructs to UV irradiation, a hydrogel matrix presenting a gradient composition is finally formed. This versatile technique was successfully used to gradually vary the physical properties ${ }^{98,99}$ as well as the chemical composition $^{100}$ of hydrogel supports in a 3D fashion (Fig. 9b).

Similarly to this method, the groups of Langer and Netti applied a multichannel, microfluidic device to gradually vary RGD (Arg-Gly-Asp) concentration within a precursor PEG-based solution for hydrogel fabrication. Subsequent photocuring of the so-formed pre-polymer mixture allowed to fix the RGD gradient across the hydrogel construct. ${ }^{70,101}$

Following an analogous method, hydrogels with a 3D variation of composition could be fabricated using a multiple syringe setup. ${ }^{102-104}$ The gradual variation of the pre-polymer solution feed from each individual syringe, followed by photocuring, enabled the fabrication of different protein concentration gradients within PEG hydrogels.

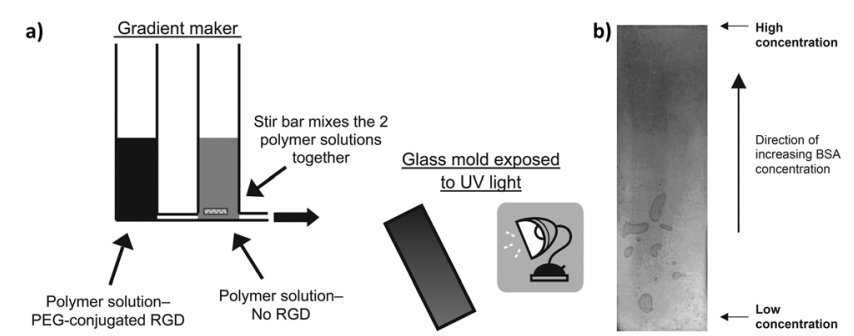

Fig. 9 (a) Schematic representation of a gradient marker used to gradually vary the concentration of RGD within a PEG solution. The resulting polymer solution is pumped into a mould where it is finally photopolymerized. (b) Representative image of a BSA-gradient hydrogel stained with Coomassie brilliant blue. Staining intensity increased with increasing concentrations of BSA. Adapted from ref. 6, Copyright 2005, with permission from Elsevier. 

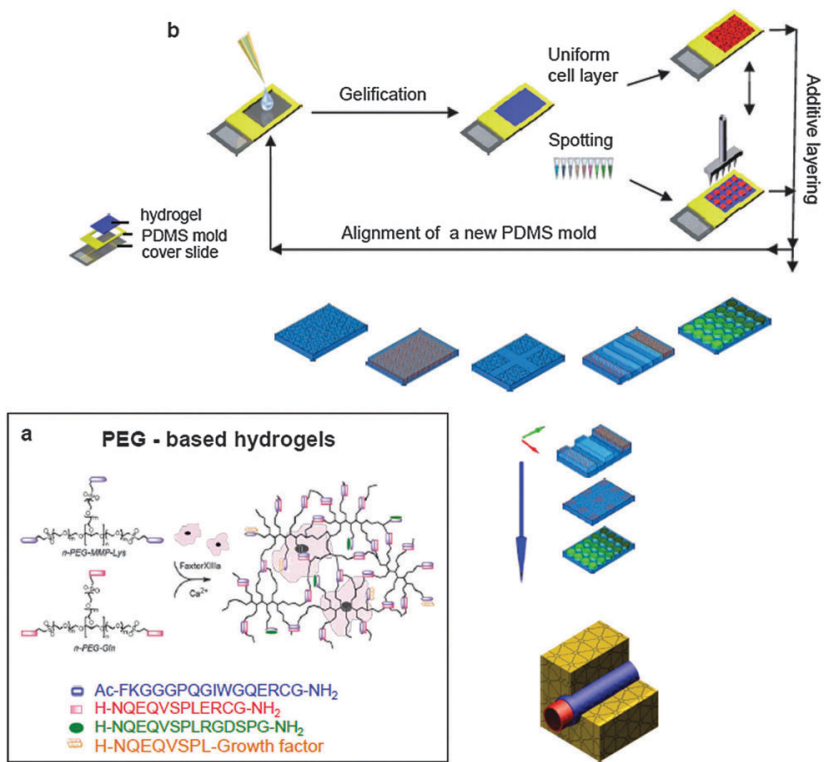

Fig. 10 Fabrication of the artificial tissue-like construct proposed by Weber and co-workers. (a) The components of the artificial extracellular matrix (aECM) applied for the hydrogel formulation. (b) A first layer of PEGbased hydrogel is casted with the help of a PDMS mask, then combinations of cells, biomolecules, and hydrogels are deposited as either uniform or patterned layers. By repetitive alignment of the PDMS moulds different heterogeneous designs are formed. The final layer-by-layer assembly of individually patterned layers results in a tissue-like construct. Reprinted from ref. 105 with permission of The Royal Society of Chemistry.

The construction of more complex architectures including organizations of cells, matrix components, and biological cues by controlled deposition of hydrogel precursors was proposed by Weber et al., who combined 3D printing with layer-by-layer patterning of diverse ECM constituents (Fig. 10). ${ }^{105}$ This process consisted of a sequential deposition of a PDMS mould containing a precursor solution, a layer of PEG hydrogel and a patterned or uniform layer of a combination of cells, biomolecules and hydrogel materials.

By repeatedly depositing these components in a layer-bylayer fashion, a complex 3D construct featuring a continuous variation of bio-components and synthetic materials was finally obtained. Although sometimes expensive and often complicated, these engineering approaches allowed producing artificial constructs closely mimicking the intrinsic compositional and physical diversities of the natural ECM.

As an alternative to fabrication methods involving sequential depositions of pre-hydrogel mixtures, photochemical patterning was successfully applied to spatially control the composition of hydrogel matrices in 3D, throughout already formed constructs. For instance, the local photoactivation of specific chemical functions allowed the spatially controlled conjugation of different peptides or proteins within hydrogel supports. This general strategy was addressed by involving diverse chemical triggers for bioconjugation, such as radical photoinitators, ${ }^{106-109}$ thiolene couplings, ${ }^{110-112}$ enzymatic $^{113}$ or thiol/amine-maleimide reactions. ${ }^{114,115}$ As an example, several studies reported the

fabrication of 3D gradients of RGD and different proteins, also including the formation of gradient patterns with different geometry and complexity within PEG-based hydrogels by spatially modulating the photocleavage of carbamate and chemically protected thiol groups within a pre-synthesized matrix. ${ }^{116}$ PEG-based hydrogels presenting 3D gradients of proteins were alternatively fabricated by the group of Ehrbar by combining electrochemistry with $\mathrm{pH}$-dependent enzymatic polymerization. ${ }^{117}$

In this process, two electrodes were immersed within a hydrogel precursor solution based on transglutaminase (TG)/PEG/ protein mixtures. The subsequent application of a potential between the cathode and the anode induced a progressive $\mathrm{pH}$ variation across the pre-hydrogel that eventually modulated the rate of enzymatic crosslinking along the construct. This resulted in the formation of $3 \mathrm{D}$ gradients of protein concentration throughout the matrix, the biomolecules being incorporated within the network structure via crosslinkable linkages. Further organization of the electrodes according to specific pattern designs and the additional application of multiple protein solutions resulted in the production of hydrogel scaffolds presenting complex and multiple 3D gradients of different proteins.

\section{Cellular response on gradient supports}

When cells from different origins are incubated in contact with synthetic ECMs featuring multidimensional gradients of peptides and protein cues, their behavior can be markedly altered. Namely, different cellular processes including migration, proliferation and differentiation can be efficiently regulated by bio-chemical gradients. ${ }^{118-120}$

It is well known that cells adhere to the surrounding ECM via cellular receptors like integrins and other adhesion proteins. ${ }^{121,122}$ These receptors probe the ECM and trigger specific responses depending on the environment, later on determining a number of cellular mechanisms. ${ }^{118,119,123}$

When studied on 2D supports, cell adhesion significantly depends on the concentration and distribution of ligands at the surface and a critical ligand spacing was found to induce maximum cell spreading and guarantee stable attachment. ${ }^{124-127}$ The adhesion of human foreskin fibroblasts on surface gradients of PLL-g-PEGsupported Fgn confirmed that a maximum of cell adhesion was found at a very specific protein spacing $(47 \pm 3 \mathrm{~nm}),{ }^{57}$ which was very close to the value initially recorded by Spatz and co-workers on RGD-nanopatterned platforms $(58 \mathrm{~nm}) .{ }^{125}$ In accordance with these findings, when the adhesion of fibroblasts was investigated on PHEMA brush-supported FN gradients, maximum values of cell adhesion and cell spreading area were recorded on areas along the gradient characterized by protein coverages of 50 and $100 \mathrm{ng} \mathrm{cm}^{-2}$, respectively. ${ }^{41}$

In addition to adhesion, the migration of cells on flat surfaces was also found very sensitive to variations of the surface coverage of protein cues and cell-adhesive peptides. In 1989 Brandley and Schnaar were the first to investigate the effect of a linear and exponential gradient of RGD surface coverage on cell adhesion and migration. ${ }^{128}$ These studies highlighted how cell migration is 
always taking place in the direction of higher peptide surface densities and, thus, towards areas with a more marked celladhesive character. In addition, steeper surface gradients of adhesive cues stimulated longer fibroblast migrations and faster cell locomotion. ${ }^{6,101}$ Similarly to surface gradients of adhesive cues, a gradual variation of basic fibroblast growth factor (bFGF) concentration on PEG-RGD-based hydrogels induced the mobility of vascular smooth muscle cells (VSMCs). Specifically, VSMCs showed an aligned morphology and moved in the direction of increasing bFGF concentration. ${ }^{7}$ In a similar way, the application of a gradient of GF concentration throughout a loosely crosslinked agarose-based hydrogel, with increasing protein concentration from the outer surface towards the core of the structure, stimulated the migration of neural precursor cells (NPCs) inside the construct. ${ }^{114,129-131}$

Cells cultured within 3D supports showed different and more complex mechanisms of migration when compared to planar substrates. $^{132,133}$ Especially within hydrogel-based ECMs, the composition and concentration of biological cues in combination with the physical properties of the polymer matrix (e.g. degree of crosslinking) were found to be crucial parameters determining the motility of cells. ${ }^{134}$ As an example, Kyburz et al. showed that hydrogels with low crosslink density $(0.18 \pm 0.02 \mathrm{mM})$ and high RGD concentration ( $1 \mathrm{mM}$ CRGDS) allowed relatively high migration rates $\left(17.6 \pm 0.9 \mu \mathrm{m} \mathrm{h}^{-1}\right) .{ }^{135}$ Alternatively, electrospun scaffolds based on poly(lactide-co-glycolide) (PLGA) and featuring a unidirectional gradient of fiber-encapsulated bFGF, directed the migration and stimulated the differentiation of mouse dermal fibroblasts in a spatially defined manner. ${ }^{85}$ The "depth" of cell migration through the fibrous support was determined by the steepness of the concentration gradient of bFGF. Additionally, when these supports were applied in vivo, the morphology of the protein gradient within the fibers also regulated the density of the subsequently formed blood vessels (Fig. 11).

Synthetic ECMs presenting different gradients of biochemical cues were also applied to spatially control the osteogenic differentiation of seeded cells within bone/cartilage implants. ${ }^{136}$ Similar supports were designed by the group of $\mathrm{Li}$, who decorated a poly(DL-lactide) (PDLLA) electrospun construct with a gradient of gelatin and hydroxyapatite (HAP). Subsequent incubation of the gradient scaffolds with pre-osteoblasts, MC-3T3 E1, demonstrated how cell viability as well as cell density could be spatially modulated according to the gradual variation of gelatin concentration. ${ }^{88}$ In addition, both alkaline phosphatase (ALP) activity and collagen type-I expression by MC-3T3 E1 showed a similar trend, indicating that the extent of osteogenic differentiation was regulated in response to the HAP gradient across the scaffold.

Applying a similar designing concept, Zhang et al. fabricated an electrospun PLGA scaffold containing a dexamethasone (Dex) gradient within the fibrous construct by complementing the electrospinning polymer solution with a variable concentration of Dex. ${ }^{78}$ Hence, the local variation in Dex release at different volumes within the scaffold directed the differentiation of subsequently incubated mesenchymal stem cells (MSCs) (Fig. 12). At positions of higher Dex concentration across the
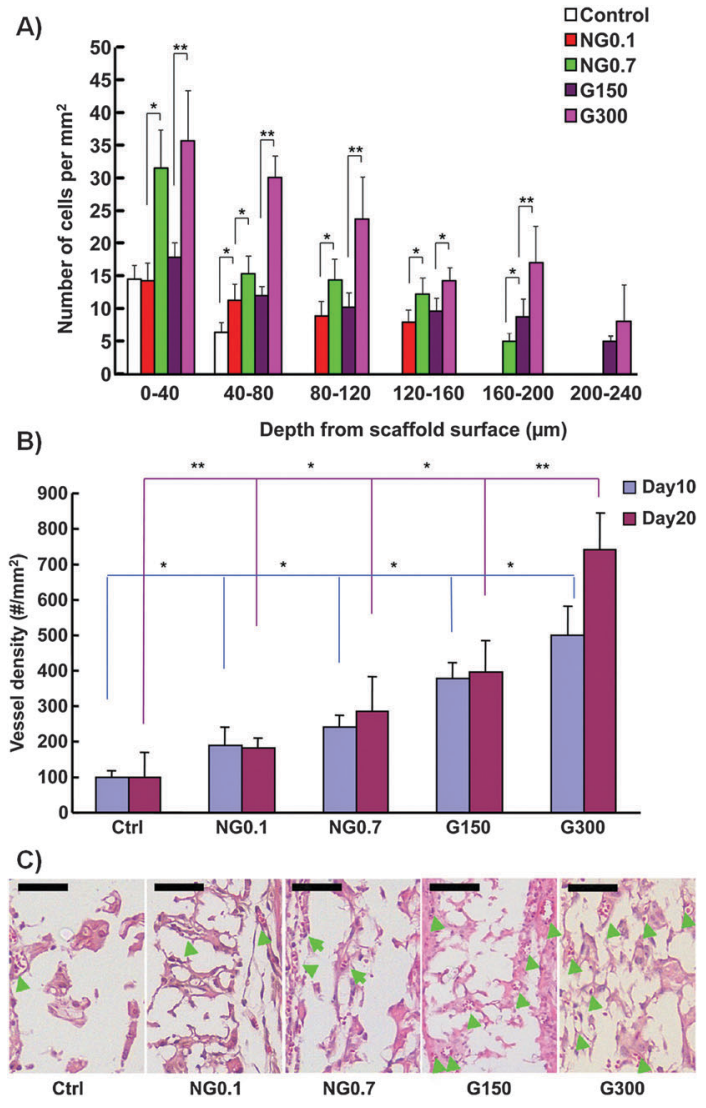

Fig. 11 (A) Number of cells at different depths from the scaffold surface after 14 days of culture $\left({ }^{*} p<0.01,{ }^{* \star} p<0.001\right)$ quantified for NG0.1 and NG0.7 (uniform scaffolds fabricated with injection rates of 0.1 and $0.7 \mathrm{ml} \mathrm{h}^{-1}$, respectively, from a $150 \mu \mathrm{g} \mathrm{ml}^{-1} \mathrm{bFGF}$ solution) and for G150 and G300 (gradient scaffolds fabricated by gradually varying the injection rate from 0.7 and $0.1 \mathrm{ml} \mathrm{h}^{-1}$ from a 150 or $300 \mu \mathrm{g} \mathrm{ml}^{-1}$ bFGF solution, respectively). (B) Number of vessels within the different scaffolds after 10 and 20 days of subcutaneous implantation $\left({ }^{*} p<0.01,{ }^{* *} p<0.001\right.$ ). (C) Blood vessels within the different scaffolds after 10 days of implantation. The functional vessels that contain well-defined lumens and blood cells are indicated by green arrows. Scale bar $=50 \mu \mathrm{m}$. Reprinted with permission from ref. 85. Copyright 2012 American Chemical Society.

support adipogenesis was favoured, while volumes characterized by lower Dex content displayed a tendency by MSCs to undergo osteogenic differentiation (Fig. 12).

Two interpenetrating gradients of different growth factors were alternatively applied across porous PCL/Pluronic F127 membranes, previously fabricated by Lee and coworkers exploiting the "diffusion method". ${ }^{89}$ Namely, platelet-derived growth factor-b (PDGF-BB) and bone morphogenetic protein 2 (BMP-2) were deposited by heparin-mediated binding to form a double gradient of protein concentration at the exposed surface of the microporous support.

Adipose stem cells (ASCs) cultured within these constructs showed an upregulation of different tenogenic markers at membrane sections loaded with higher concentrations of PDGF-BB, while different osteogenic markers were progressively upregulated moving towards regions of the scaffold presenting higher concentrations of BMP-2. The spatially resolved 


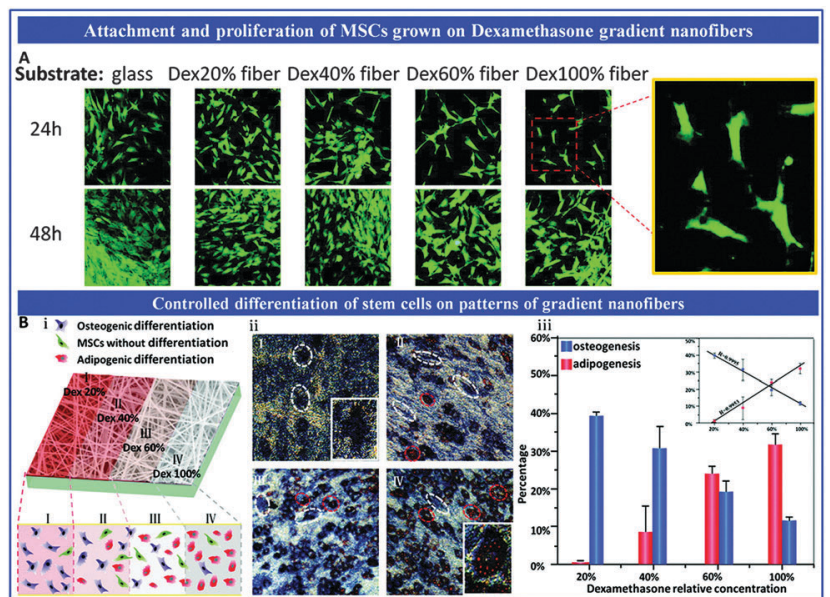

Fig. 12 (A) Fluorescence micrographs displaying MSC attachment and proliferation on dexamethasone gradient electrospun fibers. (B) MSC differentiation induced by the gradient substrates (i); (osteocyte) and red-oil (adipocyte) staining images of MSCs on fibers with dexamethasone concentration gradient (ii). Differentiation proportion of MSCs induced by the different gradient supports (iii). Reprinted with permission from ref. 78 . Copyright 2012 American Chemical Society.

differentiation of ASCs could be clearly recorded by the selective staining with antibodies against tenomodulin (for tenogenesis) and bone sialoprotein (osteogenesis).

Despite more and more knowledge being available nowadays on the most optimal ligand density to promote cell adhesion, proliferation, and migration, and on biological factors availability to influence cell differentiation in 2D and in 3D systems, further studies should aim at deepening our understanding of the biological signaling pathways that are activated when material gradients are formed. On homogenous materials, cell morphology is coupled to cell function via the activation of ROCK $^{137}$ and Hippo $^{138}$ signaling, both interrelated with the underlying substrate stiffness and the consequent dynamic remodeling of cellular FAs. On materials displaying gradients of physico-chemical and biological properties, little is known in terms of how these signaling pathways are activated and regulated in time. In this respect, it would be meaningful to monitor such biological processes also in time to assess the long-term stability of cellular adhesion and proliferation.

\section{A future perspective on gradient supports}

Although exciting results have been obtained in translating the generation of physico-chemical gradients from 2D supports to 3D scaffolds, a few challenges remain ahead. A further control on the gradient profile would be desirable to allow the creation of biological variations that mimic more closely patterns observed in native tissues and organs. This could pass, for example, through the use and control of capillary forces where we could envision creating compartments within the same 3D volume that are predisposed to solve specific sub-functions in the targeted tissue. The further possibility to combine more chemical species in the same 3D scaffold would open the door to multiplexing, thus starting to build on the biological complexity that is needed to regenerate a fully functional tissue by mimicking the different cellular niches present in our body. The use of different polymer brushes where selective chemical end groups are present to bind different biological species combined with the generation of programmed gradients could result in the selective adhesion and activity of a heterogeneous cell population. A practical example where these strategies would be meaningful to implement is the creation of a smart scaffold that allows the regeneration of a specific tissue with the integrated vascular, neural, and lymphatic networks.

In addition, next-generation scaffolds for cell manipulations are envisioned to be capable of dynamically triggering diverse cellular activities, simultaneously maintaining high specificity and modulating the trigger in space and time.

Generally, the already reported fabrication methods did not allow creating such a dynamic niche for the seeded cells. This is due to both the synthetic constituents of ECM, which must be strongly held together (covalently or physically) to host and support cells, and the (bio)chemical gradient applied on the construct, which requires to be "fixed" via an effective, fast and irreversible external stimulus (e.g. through a locally induced, prompt chemical reaction).

To overcome these limitations, the application of supramolecular building blocks to form synthetic ECMs could efficiently reproduce the dynamics of diverse cell environments. Pointing towards this challenging target, supramolecular supports for hostguest chemistries based on non-covalent interactions ${ }^{139}$ combined with SAMs have been applied to build molecularly reversible (Fig. 13) ${ }^{140}$ and stimuli-responsive biointerfaces. ${ }^{141}$

Although most of the supramolecular biointerfaces and biomaterials are designed to present a homogeneous distribution of functions, Jonkheijm et al. recently constructed protein gradients based on host-guest chemistries across a gel-statesupported lipid bilayer (SLB). ${ }^{142}$ Such SLBs showed uniform

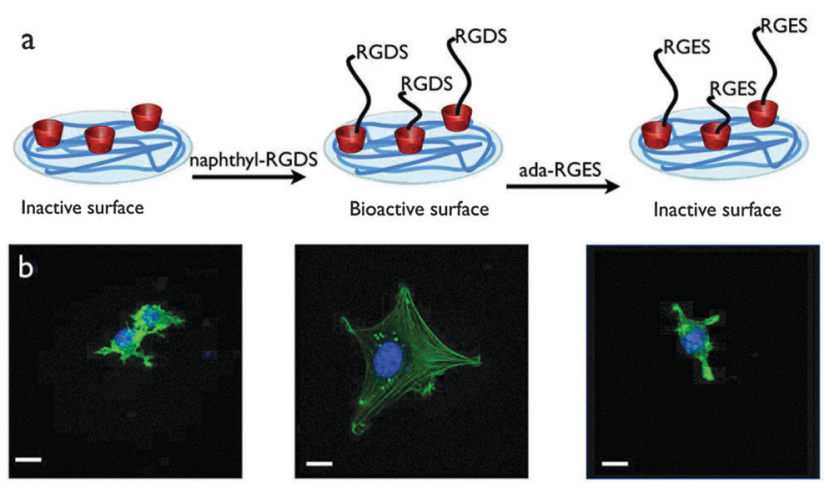

Fig. 13 (a) Supramolecular host-guest formation between cyclodextrin (red cups) and naphthyl-RGDS renders a surface bioactive. Adamantaneconjugated RGES (ada-RGES) competes with naphthyl-RGDS and makes the surface inactive. (b) Confocal microscopy of $3 T 3$ fibroblasts on the inactive surface, the activated surface and the surface with competing ada-RGES present. Scale bars represent $10 \mu \mathrm{M}$. Reprinted with permission from ref. 140. Copyright 2014 Wiley-VCH Verlag GmbH \& Co. 
coverage around room temperature, while upon heating above their melting temperature and by means of an electrophoresis setup they could originate a gradient of surface-immobilized biomolecules.

Despite these first attempts to design constructs that can function as supramolecular analogues of ECMs, further efforts need to be devoted to engineering synthetic 3D matrices which can efficiently host cell preparations and determine their fate in a spatially defined way. The fundamental advantages of the building mechanisms already proposed on flat surfaces could be adapted to a number of fabrication methods among the ones we have described in the previous paragraphs.

In addition, already tested platforms, such as bio-printed hydrogels, could be enriched by specific functions that allow host-guest interactions between the support and several added cues. From this starting point, the application of sophisticated gradient-forming fabrication methods (e.g. by employing the gradient maker) or external physical stimuli (e.g. via electrochemistry) could easily enable the formation of supramolecular gradients within the so-designed 3D scaffolds. The combination of supramolecular chemistry and the most advanced scaffold fabrication techniques would introduce the next-generation TE constructs, displaying spatial chemical diversity and tunable characteristics within the same matrix.

\section{Acknowledgements}

This work was financially supported by the MESA+ Institute for Nanotechnology of the University of Twente, by the Technology foundation STW (STW, 11135) and by the Swiss National Foundation (SNSF “Ambizione” PZ00P2-148156).

\section{References}

1 A. Seidi, M. Ramalingam, I. Elloumi-Hannachi, S. Ostrovidov and A. Khademhosseini, Acta Biomater., 2011, 7, 1441-1451.

2 J. Genzer, Annu. Rev. Mater. Res., 2012, 42, 435-468.

3 S. B. Carter, Nature, 1967, 213, 256-260.

4 S. V. Plotnikov and C. M. Waterman, Curr. Opin. Cell Biol., 2013, 25, 619-626.

5 N. Castro, S. A. Hacking and L. Zhang, Ann. Biomed. Eng., 2012, 40, 1628-1640.

6 S. A. DeLong, A. S. Gobin and J. L. West, J. Controlled Release, 2005, 109, 139-148.

7 S. A. DeLong, J. J. Moon and J. L. West, Biomaterials, 2005, 26, 3227-3234.

8 S. B. Kennedy, N. R. Washburn, C. G. Simon Jr and E. J. Amis, Biomaterials, 2006, 27, 3817-3824.

9 A. J. Engler, S. Sen, H. L. Sweeney and D. E. Discher, Cell, 2006, 126, 677-689.

10 J. M. Sobral, S. G. Caridade, R. A. Sousa, J. F. Mano and R. L. Reis, Acta Biomater., 2011, 7, 1009-1018.

11 S. Morgenthaler, C. Zink and N. D. Spencer, Soft Matter, 2008, 4, 419-434.

12 N. A. Alcantar, E. S. Aydil and J. N. Israelachvili, J. Biomed. Mater. Res., 2000, 51, 343-351.
13 I. Banerjee, R. C. Pangule and R. S. Kane, Adv. Mater., 2011, 23, 690-718.

14 A. Jain and S. K. Jain, Crit. Rev. Ther. Drug Carrier Syst., 2008, 25, 403-447.

15 F. M. Veronese and G. Pasut, Drug Discovery Today, 2005, 10, 1451-1458.

16 S. Zalipsky, Adv. Drug Delivery Rev., 1995, 16, 157-182.

17 J. Zhu, Biomaterials, 2010, 31, 4639-4656.

18 D. W. Hutmacher, Biomaterials, 2000, 21, 2529-2543.

19 S. J. Hollister, Nat. Mater., 2005, 4, 518-524.

20 Q. P. Pham, U. Sharma and A. G. Mikos, Tissue Eng., 2006, 12, 1197-1211.

21 K. Rezwan, Q. Z. Chen, J. J. Blaker and A. R. Boccaccini, Biomaterials, 2006, 27, 3413-3431.

22 T. J. Sill and H. A. von Recum, Biomaterials, 2008, 29, 1989-2006.

23 M. K. Chaudhury and G. M. Whitesides, Science, 1992, 256, 1539-1541.

24 R. H. Terrill, K. M. Balss, Y. Zhang and P. W. Bohn, J. Am. Chem. Soc., 2000, 122, 988-989.

25 Q. Wang and P. W. Bohn, J. Phys. Chem. B, 2003, 107, 12578-12584.

26 S. T. Plummer and P. W. Bohn, Langmuir, 2002, 18, 4142-4149.

27 J. C. Love, L. A. Estroff, J. K. Kriebel, R. G. Nuzzo and G. M. Whitesides, Chem. Rev., 2005, 105, 1103-1170.

28 S. T. Plummer, Q. Wang, P. W. Bohn, R. Stockton and M. A. Schwartz, Langmuir, 2003, 19, 7528-7536.

29 Q. Wang and P. W. Bohn, Thin Solid Films, 2006, 513, 338-346.

30 V. Corvaglia, R. Marega, F. De Leo, C. Michiels and D. Bonifazi, Small, 2016, 12, 321-329.

31 S. Morgenthaler, S. Lee, S. Zürcher and N. D. Spencer, Langmuir, 2003, 19, 10459-10462.

32 T. Wu, K. Efimenko, P. Vlček, V. Šubr and J. Genzer, Macromolecules, 2003, 36, 2448-2453.

33 S. Edmondson, V. L. Osborne and W. T. S. Huck, Chem. Soc. Rev., 2004, 33, 14-22.

34 X. Wang, H. Tu, P. V. Braun and P. W. Bohn, Langmuir, 2006, 22, 817-823.

35 R. Barbey, L. Lavanant, D. Paripovic, N. Schuwer, C. Sugnaux, S. Tugulu and H. A. Klok, Chem. Rev., 2009, 109, 5437-5527.

36 T. Wu, P. Gong, I. Szleifer, P. Vlček, V. Šubr and J. Genzer, Macromolecules, 2007, 40, 8756-8764.

37 P. G. De Gennes, Macromolecules, 1980, 13, 1069-1075.

38 W. J. Brittain and S. Minko, J. Polym. Sci., Part A: Polym. Chem., 2007, 45, 3505-3512.

39 T. Wu, K. Efimenko and J. Genzer, J. Am. Chem. Soc., 2002, 124, 9394-9395.

40 Y. Mei, T. Wu, C. Xu, K. J. Langenbach, J. T. Elliott, B. D. Vogt, K. L. Beers, E. J. Amis and N. R. Washburn, Langmuir, 2005, 21, 12309-12314.

41 Y. Mei, J. T. Elliott, J. R. Smith, K. J. Langenbach, T. Wu, C. Xu, K. L. Beers, E. J. Amis and L. Henderson, J. Biomed. Mater. Res., Part A, 2006, 79, 974-988.

42 T. Ren, S. Yu, Z. Mao, S. E. Moya, L. Han and C. Gao, Biomacromolecules, 2014, 15, 2256-2264. 
43 S. Choi, B. C. Choi, C. Xue and D. Leckband, Biomacromolecules, 2013, 14, 92-100.

44 K. Vasilev, A. Mierczynska, A. L. Hook, J. Chan, N. H. Voelcker and R. D. Short, Biomaterials, 2010, 31, 392-397.

$45 \mathrm{~J}$. Wu, Z. Mao and C. Gao, Biomaterials, 2012, 33, 810-820.

46 R. R. Bhat, B. N. Chaney, J. Rowley, A. Liebmann-Vinson and J. Genzer, Adv. Mater., 2005, 17, 2802-2807.

47 M. R. Tomlinson and J. Genzer, Chem. Commun., 2003, 1350-1351.

48 L. Li, Y. Zhu, B. Li and C. Gao, Langmuir, 2008, 24, 13632-13639.

49 R. Bhat, M. Tomlinson, T. Wu and J. Genzer, in SurfaceInitiated Polymerization II, ed. R. Jordan, Springer, Berlin Heidelberg, 2006, vol. 198, ch. 60, pp. 51-124.

50 M. R. Tomlinson and J. Genzer, Macromolecules, 2003, 36, 3449-3451.

51 M. Klein Gunnewiek, S. N. Ramakrishna, A. Di Luca, G. J. Vancso, L. Moroni and E. M. Benetti, Adv. Mater. Interfaces, 2016, 3, 1500456.

52 B. Trappmann, J. E. Gautrot, J. T. Connelly, D. G. T. Strange, Y. Li, M. L. Oyen, M. A. Cohen Stuart, H. Boehm, B. Li, V. Vogel, J. P. Spatz, F. M. Watt and W. T. S. Huck, Nat. Mater., 2012, 11, 642-649.

53 N. Huebsch, P. R. Arany, A. S. Mao, D. Shvartsman, O. A. Ali, S. A. Bencherif, J. Rivera-Feliciano and D. J. Mooney, Nat. Mater., 2010, 9, 518-526.

54 A. P. Kourouklis, R. V. Lerum and H. Bermudez, Biomaterials, 2014, 35, 4827-4834.

55 S. Tugulu, P. Silacci, N. Stergiopulos and H.-A. Klok, Biomaterials, 2007, 28, 2536-2546.

56 S. Morgenthaler, C. Zink, B. Städler, J. Vörös, S. Lee, N. D. Spencer and S. G. P. Tosatti, Biointerphases, 2006, 1, 156-165.

57 J. Pei, H. Hall and N. D. Spencer, Biomaterials, 2011, 32, 8968-8978.

58 A. Halperin, Langmuir, 1999, 15, 2525-2533.

59 M. Müller, S. Lee, H. Spikes and N. Spencer, Tribol. Lett., 2003, 15, 395-405.

60 J. W. Lussi, D. Falconnet, J. A. Hubbell, M. Textor and G. Csucs, Biomaterials, 2006, 27, 2534-2541.

61 M. Jaspers, M. Dennison, M. F. J. Mabesoone, F. C. MacKintosh, A. E. Rowan and P. H. J. Kouwer, Nat. Commun., 2014, 5.

62 S. T. K. Raja, T. Thiruselvi, A. B. Mandal and A. Gnanamani, Sci. Rep., 2015, 5, 15977.

63 I. Caelen, A. Bernard, D. Juncker, B. Michel, H. Heinzelmann and E. Delamarche, Langmuir, 2000, 16, 9125-9130.

64 N. L. Jeon, S. K. W. Dertinger, D. T. Chiu, I. S. Choi, A. D. Stroock and G. M. Whitesides, Langmuir, 2000, 16, 8311-8316.

65 R. C. Gunawan, E. R. Choban, J. E. Conour, J. Silvestre, L. B. Schook, H. R. Gaskins, D. E. Leckband and P. J. A. Kenis, Langmuir, 2005, 21, 3061-3068.

66 S. Kim, H. J. Kim and N. L. Jeon, Integr. Biol., 2010, 2, 584-603. 67 A. G. Toh, Z. P. Wang, C. Yang and N.-T. Nguyen, Microfluid. Nanofluid., 2014, 16, 1-18.

68 K. A. Fosser and R. G. Nuzzo, Anal. Chem., 2003, 75, 5775-5782.
69 J. He, Y. Du, J. L. Villa-Uribe, C. Hwang, D. Li and A. Khademhosseini, Adv. Funct. Mater., 2010, 20, 131-137.

70 J. A. Burdick, A. Khademhosseini and R. Langer, Langmuir, 2004, 20, 5153-5156.

71 X. Jiang, Q. Xu, S. K. W. Dertinger, A. D. Stroock, T.-m. Fu and G. M. Whitesides, Anal. Chem., 2005, 77, 2338-2347.

72 R. C. Gunawan, J. Silvestre, H. R. Gaskins, P. J. A. Kenis and D. E. Leckband, Langmuir, 2006, 22, 4250-4258.

73 S. Allazetta, S. Cosson and M. P. Lutolf, Chem. Commun., 2011, 47, 191-193.

74 S. Cosson, S. Allazetta and M. P. Lutolf, Lab Chip, 2013, 13, 2099-2105.

75 S. Cosson, S. A. Kobel and M. P. Lutolf, Adv. Funct. Mater., 2009, 19, 3411-3419.

76 D. H. Reneker and A. L. Yarin, Polymer, 2008, 49, 2387-2425.

77 Handarmin, G. J. Y. Tan, B. Sundaray, G. T. Marcy, E. L. K. Goh and S. Y. Chew, Drug Delivery Transl. Res., 2011, 1, 147-160.

78 X. Zhang, X. Gao, L. Jiang and J. Qin, Langmuir, 2012, 28, 10026-10032.

79 H. G. Sundararaghavan and J. A. Burdick, Biomacromolecules, 2011, 12, 2344-2350.

80 S. Samavedi, C. Olsen Horton, S. A. Guelcher, A. S. Goldstein and A. R. Whittington, Acta Biomater., 2011, 7, 4131-4138.

81 W. Bonani, D. Maniglio, A. Motta, W. Tan and C. Migliaresi, J. Biomed. Mater. Res., Part B, 2011, 96, 276-286.

82 S. Samavedi, S. A. Guelcher, A. S. Goldstein and A. R. Whittington, Biomaterials, 2012, 33, 7727-7735.

83 W. Bonani, A. Motta, C. Migliaresi and W. Tan, Langmuir, 2012, 28, 13675-13687.

84 F. Du, H. Wang, W. Zhao, D. Li, D. Kong, J. Yang and Y. Zhang, Biomaterials, 2012, 33, 762-770.

85 X. Guo, C. G. Elliott, Z. Li, Y. Xu, D. W. Hamilton and J. Guan, Biomacromolecules, 2012, 13, 3262-3271.

86 X. Li, J. Xie, J. Lipner, X. Yuan, S. Thomopoulos and Y. Xia, Nano Lett., 2009, 9, 2763-2768.

87 J. Shi, L. Wang, F. Zhang, H. Li, L. Lei, L. Liu and Y. Chen, ACS Appl. Mater. Interfaces, 2010, 2, 1025-1030.

88 B. Zou, Y. Liu, X. Luo, F. Chen, X. Guo and X. Li, Acta Biomater., 2012, 8, 1576-1585.

89 H. K. Min, S. H. Oh, J. M. Lee, G. I. Im and J. H. Lee, Acta Biomater., 2014, 10, 1272-1279.

90 S. H. Oh, J. H. Kim, J. M. Kim and J. H. Lee, J. Biomater. Sci., Polym. Ed., 2006, 17, 1375-1387.

91 S. H. Oh, I. K. Park, J. M. Kim and J. H. Lee, Biomaterials, 2007, 28, 1664-1671.

92 S. H. Oh, T. H. Kim, G. I. Im and J. H. Lee, Biomacromolecules, 2010, 11, 1948-1955.

93 T. Kim, S. Oh, E. Kwon, J. Lee and J. Lee, Macromol. Res., 2013, 21, 878-885.

94 S. H. Oh, T. H. Kim and J. H. Lee, Biomaterials, 2011, 32, 8254-8260.

95 L. Moroni, J. R. de Wijn and C. A. van Blitterswijk, J. Biomed. Mater. Res., Part A, 2005, 75, 957-965. 
96 L. Moroni, J. R. de Wijn and C. A. van Blitterswijk, Biomaterials, 2006, 27, 974-985.

97 M. Klein Gunnewiek, A. Di Luca, H. Z. Bollemaat, C. A. van Blitterswijk, G. J. Vancso, L. Moroni and E. M. Benetti, Adv. Healthcare Mater., 2015, 4, 1169-1174.

98 K. Chatterjee, S. Lin-Gibson, W. E. Wallace, S. H. Parekh, Y. J. Lee, M. T. Cicerone, M. F. Young and C. G. Simon Jr, Biomaterials, 2010, 31, 5051-5062.

99 S. Nemir, H. N. Hayenga and J. L. West, Biotechnol. Bioeng., 2010, 105, 636-644.

100 X. Wang, E. Wenk, X. Zhang, L. Meinel, G. VunjakNovakovic and D. L. Kaplan, J. Controlled Release, 2009, 134, 81-90.

101 D. Guarnieri, A. De Capua, M. Ventre, A. Borzacchiello, C. Pedone, D. Marasco, M. Ruvo and P. A. Netti, Acta Biomater., 2010, 6, 2532-2539.

102 L. A. Smith Callahan, E. P. Childers, S. L. Bernard, S. D. Weiner and M. L. Becker, Acta Biomater., 2013, 9, 7420-7428.

103 L. A. Smith Callahan, A. M. Ganios, E. P. Childers, S. D. Weiner and M. L. Becker, Acta Biomater., 2013, 9, 6095-6104.

104 L. A. Smith Callahan, G. M. Policastro, S. L. Bernard, E. P. Childers, R. Boettcher and M. L. Becker, Biomacromolecules, 2013, 14, 3047-3054.

105 A. Sala, P. Hanseler, A. Ranga, M. P. Lutolf, J. Vörös, M. Ehrbar and F. E. Weber, Integr. Biol., 2011, 3, 1102-1111.

106 M. S. Hahn, J. S. Miller and J. L. West, Adv. Mater., 2005, 17, 2939-2942.

107 M. S. Hahn, J. S. Miller and J. L. West, Adv. Mater., 2006, 18, 2679-2684.

108 M. S. Hahn, L. J. Taite, J. J. Moon, M. C. Rowland, K. A. Ruffino and J. L. West, Biomaterials, 2006, 27, 2519-2524.

109 J. C. Hoffmann and J. L. West, Soft Matter, 2010, 6, 5056-5063.

110 B. D. Polizzotti, B. D. Fairbanks and K. S. Anseth, Biomacromolecules, 2008, 9, 1084-1087.

111 C. A. DeForest and K. S. Anseth, Nat. Chem., 2011, 3, 925-931.

112 C. A. DeForest and K. S. Anseth, Angew. Chem., Int. Ed., 2012, 51, 1816-1819.

113 K. A. Mosiewicz, L. Kolb, A. J. van der Vlies, M. M. Martino, P. S. Lienemann, J. A. Hubbell, M. Ehrbar and M. P. Lutolf, Nat. Mater., 2013, 12, 1072-1078.

114 R. G. Wylie, S. Ahsan, Y. Aizawa, K. L. Maxwell, C. M. Morshead and M. S. Shoichet, Nat. Mater., 2011, 10, 799-806.

115 R. G. Wylie and M. S. Shoichet, Biomacromolecules, 2011, 12, 3789-3796.

116 S. Khetan and J. A. Burdick, Soft Matter, 2011, 7, 830-838.

117 V. Milleret, B. R. Simona, P. S. Lienemann, J. Vörös and M. Ehrbar, Adv. Healthcare Mater., 2014, 3, 508-514.

118 E. Cukierman, R. Pankov and K. M. Yamada, Curr. Opin. Cell Biol., 2002, 14, 633-640.
119 M. A. Wozniak, K. Modzelewska, L. Kwong and P. J. Keely, Biochim. Biophys. Acta, Mol. Cell Res., 2004, 1692, 103-119.

120 S. I. Fraley, Y. Feng, R. Krishnamurthy, D.-H. Kim, A. Celedon, G. D. Longmore and D. Wirtz, Nat. Cell Biol., 2010, 12, 598-604.

121 B. Geiger, J. P. Spatz and A. D. Bershadsky, Nat. Rev. Mol. Cell Biol., 2009, 10, 21-33.

122 M. Prager-Khoutorsky, A. Lichtenstein, R. Krishnan, K. Rajendran, A. Mayo, Z. Kam, B. Geiger and A. D. Bershadsky, Nat. Cell Biol., 2011, 13, 1457-1465.

123 S. I. Fraley, Y. Feng, R. Krishnamurthy, D. H. Kim, A. Celedon, G. D. Longmore and D. Wirtz, Nat. Cell Biol., 2010, 12, 598-604.

124 E. A. Cavalcanti-Adam, A. Micoulet, J. Blümmel, J. Auernheimer, H. Kessler and J. P. Spatz, Eur. J. Cell Biol., 2006, 85, 219-224.

125 E. A. Cavalcanti-Adam, T. Volberg, A. Micoulet, H. Kessler, B. Geiger and J. P. Spatz, Biophys. J., 2007, 92, 2964-2974.

126 P. A. Underwood and F. A. Bennett, J. Cell Sci., 1989, 93, 641-649.

127 Y. N. Danilov and R. L. Juliano, Exp. Cell Res., 1989, 182, 186-196.

128 B. K. Brandley and R. L. Schnaar, Dev. Biol., 1989, 135, 74-86.

129 E. M. Levine, H. Roelink, J. Turner and T. A. Reh, J. Neurosci., 1997, 17, 6277-6288.

130 M. Fu, V. C. H. Lui, M. H. Sham, V. Pachnis and P. K. H. Tam, J. Cell Biol., 2004, 166, 673-684.

131 E. Angot, K. Loulier, K. T. Nguyen-Ba-Charvet, A. P. Gadeau, M. Ruat and E. Traiffort, Stem Cells, 2008, 26, 2311-2320.

132 E. Cukierman, R. Pankov, D. R. Stevens and K. M. Yamada, Science, 2001, 294, 1708-1712.

133 R. J. Petrie, N. Gavara, R. S. Chadwick and K. M. Yamada, J. Cell Biol., 2012, 197, 439-455.

134 S. Even-Ram and K. M. Yamada, Curr. Opin. Cell Biol., 2005, 17, 524-532.

135 K. A. Kyburz and K. S. Anseth, Acta Biomater., 2013, 9, 6381-6392.

136 P. C. Bessa, M. Casal and R. L. Reis, J. Tissue Eng. Regener. Med., 2008, 2, 81-96.

137 R. McBeath, D. M. Pirone, C. M. Nelson, K. Bhadriraju and C. S. Chen, Dev. Cell, 2004, 6, 483-495.

138 S. Dupont, L. Morsut, M. Aragona, E. Enzo, S. Giulitti, M. Cordenonsi, F. Zanconato, J. Le Digabel, M. Forcato, S. Bicciato, N. Elvassore and S. Piccolo, Nature, 2011, 474, 179-183.

139 H.-J. Schneider, Angew. Chem., Int. Ed., 2009, 48, 3924-3977. 140 J. Boekhoven and S. I. Stupp, Adv. Mater., 2014, 26, 1642-1659. 141 H. Yang, B. Yuan, X. Zhang and O. A. Scherman, Acc. Chem. Res., 2014, 47, 2106-2115.

142 J. Cabanas-Danés, E. D. Rodrigues, E. Landman, J. van Weerd, C. van Blitterswijk, T. Verrips, J. Huskens, M. Karperien and P. Jonkheijm, J. Am. Chem. Soc., 2014, 136, 12675-12681. 